\title{
Transcatheter aortic valve insertion after previous mitral valve operation
}

\author{
Kevin L. Greason, MD, ${ }^{a}$ Gurpreet S. Sandhu, MD, PhD, ${ }^{b}$ Vuyisile T. Nkomo, MD, MPH, ${ }^{b}$ \\ Katherine S. King, MS, ${ }^{\mathrm{c}}$ David L. Joyce, MD, ${ }^{\mathrm{a}}$ Eric E. Williamson, MD, ${ }^{\mathrm{d}}$ and David R. Holmes, MD ${ }^{\mathrm{b}}$
}

\section{ABSTRACT}

Objective: There are limited data on transcatheter aortic valve insertion after previous mitral valve operation. To better understand the associated procedural risks, we reviewed our single-center experience.

Methods: We retrospectively reviewed the records of 772 consecutive patients who received transcatheter aortic valve insertion from November 2008 through August 2016. There were $18(2 \%)$ patients who had previous mitral valve operation that included valve repair in 4 patients $(22 \%)$ and replacement in 14 $(78 \%)$.

Results: Baseline characteristics included age of 77 years (interquartile range 68, 84), female sex in 11 patients $(61 \%)$, New York Heart Association functional class III/IV in $14(78 \%)$, and Society of Thoracic Surgeons predicted risk of mortality of $7.0 \%(5.3,12.0)$. Access was transfemoral in 14 patients $(78 \%)$. Valve insertion was successful in all patients and involved a balloon expandable device in $10(56 \%)$. No patient experienced acute mitral valve dysfunction or procedure-related mortality. Follow-up echocardiography demonstrated mean systolic aortic valve gradient of $9 \mathrm{~mm} \mathrm{Hg}(8,12)$, no grade moderate or greater aortic paravalvular regurgitation, and stable mitral valve function. Kaplan-Meier estimated survival was $90.9 \% \pm 9.1 \%$ at 1 year.

Conclusions: Transcatheter aortic valve insertion appears to be a safe and effective operation after previous mitral valve operation. Procedure success was achieved with both balloon expandable and self-expanding devices and was independent of arterial access method. Transcatheter valve insertion should not be denied strictly on the basis of a previous mitral valve operation. ( $\mathrm{J}$ Thorac

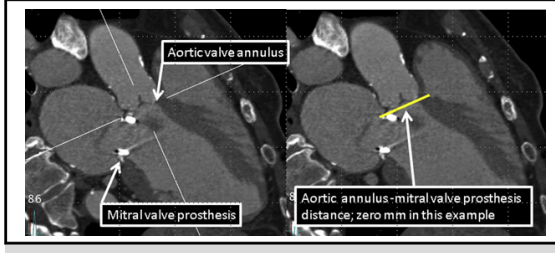

Aortic annulus and mechanical mitral valve prosthesis interface and distance.

\section{Central Message}

Transcatheter aortic valve insertion is safe and effective in the setting of previous mitral valve operation.

\section{Perspective}

Transcatheter aortic valve insertion was successful without mitral valve dysfunction or perioperative mortality in this series of patients after previous mitral valve operation. Intermediate-term follow-up demonstrated stable aortic and mitral valve function. Transcatheter aortic valve insertion appears to be a safe and effective operation in this setting.

See Editorial Commentary pages 816 and 818 . Cardiovasc Surg 2017;154:810-5)

Transcatheter aortic valve insertion is an evolving treatment strategy for aortic valve stenosis. The safety and efficacy of the procedure has been intensively examined in 5 prospective studies, 4 of which were randomized. ${ }^{1-5}$ In each of the studies, however, previous heart valve replacement was an exclusion criterion. Consequently, there has been limited experience with transcatheter valve insertion after previous mitral valve operation, with most published information being case reports or small case

From the Departments of ${ }^{\mathrm{a} C a r d i o v a s c u l a r}$ Surgery, ${ }^{\mathrm{b}}$ Cardiovascular Diseases, and ${ }^{\mathrm{d}}$ Radiology, and ${ }^{\mathrm{c}}$ Division of Biomedical Statistics and Informatics, Mayo Clinic, Rochester, Minn.

Received for publication Sept 11, 2016; revisions received Feb 11, 2017; accepted for publication March 15, 2017; available ahead of print May 5, 2017.

Address for reprints: Kevin L. Greason, MD, Department of Cardiovascular Surgery, Mayo Clinic, Rochester, MN 55905 (E-mail: greason.kevin@mayo.edu).

0022-5223/\$36.00

Copyright (c) 2017 by The American Association for Thoracic Surgery

http://dx.doi.org/10.1016/j.jtcvs.2017.03.118 series. $^{6-16}$ We hypothesized that transcatheter aortic valve insertion could be safely performed in such a circumstance. To better understand the associated procedural risks and outcomes, we reviewed our singlecenter experience.

\section{METHODS}

The institutional review board approved this study. We retrospectively reviewed the records of 772 consecutive patients who received transcatheter aortic valve insertion by our multidisciplinary heart team from November 2008 through August 2016. There were 18 (2\%) patients who had previous mitral valve operation, and these patients formed the

Scanning this QR code will take you to a supplemental video for the article. 


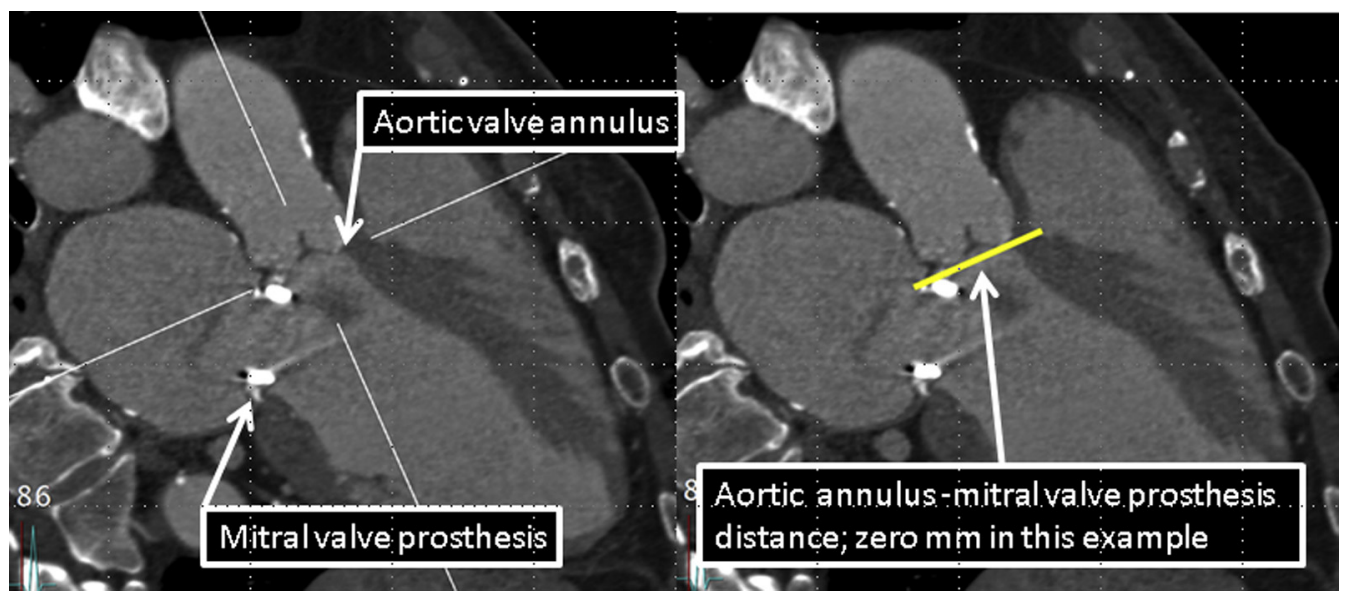

FIGURE 1. Aortic annulus and mechanical mitral valve prosthesis interface. The aortic valve annulus and mitral valve prosthesis are marked. The yellow line represents the aortic annulus-mitral valve prosthesis distance. In this patient (no. 1 in the series), the distance was 0 mm.

study cohort. Patients were managed by a multidisciplinary heart team that adhered to the transfemoral first philosophy. All patients met Food and Drug Administration/Centers for Medicare and Medicaid Services defined criteria for transcatheter aortic valve insertion.

Baseline patient characteristics, operative data, and survival data were retrieved from the electronic medical record and Division of Cardiovascular Surgery database. Data were recorded based on definitions set forth in the Society of Thoracic Surgeons Adult Cardiac Surgery Database (Chicago, Ill) and Valve Academic Research Consortium-2 consensus document. ${ }^{17}$

All patients received preoperative cardiac gated multidetector computed tomography angiography to assess the aortic valve, left ventricular outflow tract, and the relationship with the mitral valve. Specific transcatheter aortic valve types were selected at the discretion of the multidisciplinary heart team with no formal institution selection algorithm. Valve prostheses were sized based on standard recommendations provided in the respective transcatheter valve instructions for use. ${ }^{18-21}$

The position of the deployed transcatheter valve was recorded differently for the 2 types of valve devices. For balloon expandable valves, the deployment position was recorded as the percentage of valve length above and below the nadir of the noncoronary sinus just before balloon inflation (eg, 50\% above and 50\% below the nadir). For the self-expanding valves, the deployment position was recorded as the final depth of the transcatheter valve below the noncoronary sinus.

The preoperatively obtained cardiac gated multidetector computed tomography scans were retrospectively reviewed to determine the preoperative aortic annulus-mitral valve prosthesis distance. The distance was established using the following technique: the coplanar aortic annulus image was obtained and then rotated until the aortic annulus-mitral valve prosthesis distance was at a minimum, at which point a measurement was recorded (Figure 1).

Descriptive statistics are reported as count (percentage) for categorical data and median (interquartile range) for continuous data. Categorical data were analyzed with the Fischer exact test, and the Kaplan-Meier product limit method was used to estimate survival. Descriptive statistics and analyses were carried out in SAS statistical programming language (Version 9.4; SAS Institute, Inc, Cary, NC).

\section{RESULTS}

Baseline characteristics included an age of 77 years $(68,84)$, female sex in 11 patients $(61 \%)$, New York Heart Association functional class III/IV in 14 (78\%), and Society of Thoracic Surgeons predicted risk of mortality of $7.0 \%$ (5.3, 12.0). Additional Society of Thoracic Surgeons risk calculator variables are reported in Table 1.

Previous mitral valve operation occurred 12.6 years $(8.0$, 15.5) before the index transcatheter aortic valve insertion operation. Mitral valve repair had been performed in 4 patients $(22 \%)$ and replacement in 14 patients $(78 \%)$, which included a mechanical prosthesis in 10 patients and biological prosthesis in 4 patients. The aortic annulus-mitral valve prosthesis distance for all patients measured $3.5 \mathrm{~mm}$ (2.2, 5.6), and categorized by valve type measured the following: mechanical valve $4.1 \mathrm{~mm}$ (2.2, 5.6), biological valve $1.8 \mathrm{~mm}(0.5,5.4)$, and valve repair $4.2 \mathrm{~mm}(3.3,5.8)$. Baseline patient data are reported in Table 2.

All patients received successful transcatheter aortic valve insertion under general anesthesia with transesophageal echocardiography guidance (Video 1). Arterial access was transfemoral in 14 patients $(78 \%)$, transapical in 2 $(11 \%)$, and transaortic in $2(11 \%)$. Transcatheter valve types inserted included the SAPIEN (Edwards Lifesciences, Irvine, Calif) in 2 patients (11\%), SAPIEN XT (Edwards Lifesciences) in $4(22 \%)$, SAPIEN S3 (Edwards Lifesciences) in $4(22 \%)$, CoreValve (Medtronic, Minneapolis, Minn) in $4(22 \%)$, and Evolut (Medtronic) in $4(22 \%)$. No special maneuvers or techniques were undertaken during transcatheter valve insertion.

All nonrepositionable valves were deployed where planned; however, 1 of the 4 Evolut valve deployments required partial recapture and reposition to correct for moderate paravalvular regurgitation. Following repositioning of the Evolut valve, there was only mild paravalvular aortic regurgitation. Operative data are reported in Table 3. Intraoperative transesophageal echocardiography demonstrated no paravalvular aortic regurgitation in 5 patients $(28 \%)$, grade trivial in 6 
TABLE 1. Baseline patient characteristics

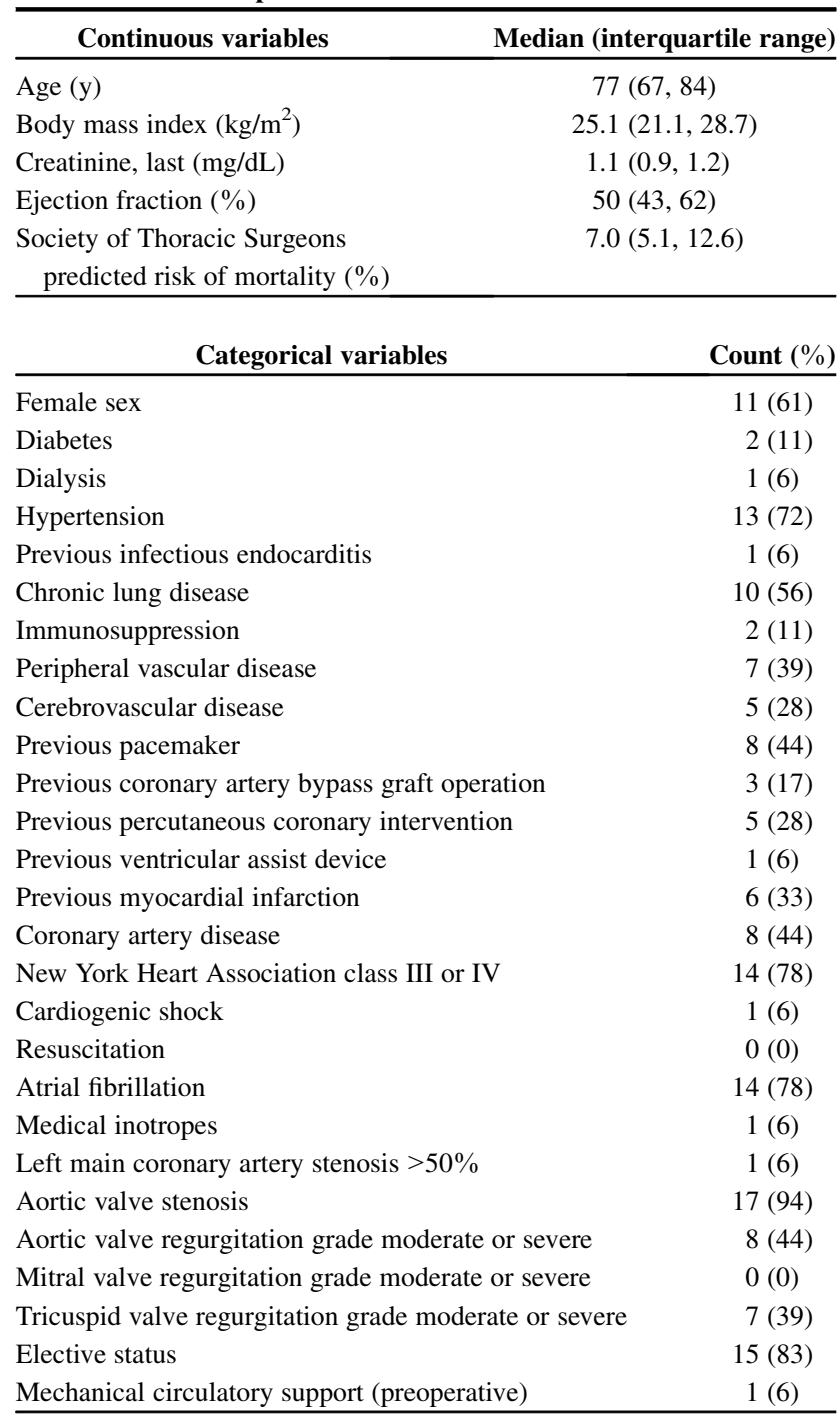

$(33 \%)$, and grade mild in $7(39 \%)$. No patient demonstrated acute change in mitral valve function.

Perioperative complications occurred in 5 patients $(28 \%)$ and included need for a new permanent pacemaker in 3 patients (3 [30\%] of 10), minor vascular access site injury in 1 , and readmission to the hospital for a transient ischemic attack in 1 . The rate of new pacemaker implantation was $129(21 \%)$ of 624 in those patients without previous mitral valve operation (compared with patients with previous mitral valve operation, $P=.491)$. Discharge disposition was to home in 15 patients $(83 \%)$, and the hospital stay was 5 days $(2,6)$. There was no in-hospital or 30-day mortality.

Echocardiography follow-up was complete in all patients at 0.2 years $(0.1,0.8)$. Mean systolic transcatheter aortic valve gradient was $9 \mathrm{~mm} \mathrm{Hg}(8,12)$, and there was no instance of grade moderate or greater paravalvular regurgitation. Comparing the preoperative and last follow-up postoperative mitral valve echocardiography, the mean diastolic mitral valve gradient changed $0 \mathrm{~mm}$ $\mathrm{Hg}$ (negative 1,0), whereas the mitral valve regurgitation grade improved in 2 patients $(11 \%)$ and remained stable in $16(89 \%)$. Postoperative echocardiography data are reported in Table 4.

Functional class follow-up was obtained in all patients at 0.3 years $(0.1,0.6)$. At that time, New York Heart Association functional class I was present in 10 patients $(56 \%)$, class II in $7(39 \%)$, and class III in $1(6 \%)$. Specific last follow-up echocardiography findings in the patient with functional class III included mean systolic aortic valve gradient of $9 \mathrm{~mm} \mathrm{Hg}$, paravalvular aortic regurgitation grade trivial, mitral valve regurgitation grade trivial, and mean diastolic mitral valve gradient of $6 \mathrm{~mm} \mathrm{Hg}$ (preoperative of $6 \mathrm{~mm} \mathrm{Hg}$ ).

Two patients died during a follow-up of 1.0 years $(0.4$, 2.0); 1 patient died at 0.7 year after operation and another at 1.4 years after operation; cause of death was unknown in both cases. The Kaplan-Meier estimated survival was $90.9 \% \pm 9.1 \%$ at 1 year.

\section{COMMENTS}

We report safe and effective transcatheter aortic valve insertion with a variety of devices and methods of access in this series of 18 patients who had previous mitral valve operation. Important outcome measures included no instances of acute or delayed mitral native valve or prosthesis injury or dysfunction, and acceptable transcatheter aortic valve function with respect to mean systolic aortic valve gradient and grade of paravalvular regurgitation. Furthermore, there were no outlier perioperative complications, and intermediate-term Kaplan-Meier estimated survival appeared reasonable at 1 year.

The pioneer transcatheter aortic valve investigators were obviously concerned with the potential peril of valve insertion after previous mitral valve replacement and excluded such patients from the pivotal studies. ${ }^{1-5}$ Subsequent isolated case reports would seem to corroborate the worry. Sarkar and colleagues ${ }^{6}$ reported a case of severe central CoreValve regurgitation due to focal under expansion of the CoreValve prosthesis across the entire interface with the mitral mechanical valve prosthesis. In another study, Testa and colleagues ${ }^{15}$ reported cardiogenic shock related to acute mechanical mitral valve dysfunction after insertion of the CoreValve prosthesis.

The negative outcomes highlight the potential mechanisms for intraoperative complications: under expansion of the transcatheter valve prosthesis due to the mitral prosthesis and interference with the functioning of the mitral prosthesis. In the case of underexpansion, Sakar and colleagues ${ }^{6}$ used aggressive postdilation valvuloplasty to successfully remedy the situation. To treat the mitral 


\begin{tabular}{|c|c|c|c|c|c|}
\hline \multirow[b]{2}{*}{ Patient } & \multirow[b]{2}{*}{ Previous mitral valve operation (prosthesis)* } & \multirow[b]{2}{*}{$\begin{array}{c}\text { Time from } \\
\text { previous mitral } \\
\text { valve operation }(\mathbf{y}) \\
\end{array}$} & \multirow[b]{2}{*}{$\begin{array}{c}\text { Aortic } \\
\text { annulus-mitral } \\
\text { prosthesis } \\
\text { distance }(\mathbf{m m}) \\
\end{array}$} & \multicolumn{2}{|c|}{ Mitral valve } \\
\hline & & & & $\begin{array}{c}\text { Mean } \\
\text { diastolic } \\
\text { gradient } \\
(\mathbf{m m ~ H g})\end{array}$ & $\begin{array}{c}\text { Regurgitation } \\
\text { grade }\end{array}$ \\
\hline 1 & Mitral valve replacement (Carbomedics, mechanical valve) & 13.9 & 0.0 & 7 & Trivial \\
\hline 2 & Mitral valve replacement (Carbomedics, mechanical valve) & 13.3 & 5.6 & 3 & Trivial \\
\hline 3 & Mitral valve repair & 8.8 & 4.4 & 6 & Mild \\
\hline 4 & Mitral valve replacement (Carbomedics, mechanical valve) & 5.8 & 0.9 & 3 & Trivial \\
\hline 5 & Mitral valve repair & 17.7 & 3.9 & 3 & Mild \\
\hline 6 & Mitral valve replacement (Hancock, biological valve) & 1.4 & 2.5 & 6 & Trivial \\
\hline 7 & Mitral valve replacement (Carbomedics, mechanical valve) & 8.0 & 2.8 & 3 & Trivial \\
\hline 8 & Mitral valve repair & 16.1 & 2.7 & 0 & Mild \\
\hline 9 & Mitral valve replacement (Perimount, biological valve) & 13.8 & 6.6 & 14 & Trivial \\
\hline 10 & Mitral valve repair & 11.2 & 6.2 & 2 & Trivial \\
\hline 11 & Mitral valve replacement (Mosaic, biological valve) & 7.9 & 0.0 & 9 & Trivial \\
\hline 12 & Mitral valve replacement (Starr-Edwards, mechanical valve) & 25.7 & 7.5 & 6 & Trivial \\
\hline 13 & Mitral valve replacement (Mosaic, biological valve) & 9.4 & 1.0 & 4 & Trivial \\
\hline 14 & Mitral valve replacement (Carbomedics, mechanical valve) & 12.0 & 3.0 & 3 & Mild \\
\hline 15 & Mitral valve replacement (St Jude, mechanical valve) & 14.1 & 5.6 & 7 & Trivial \\
\hline 16 & Mitral valve replacement (St Jude, mechanical valve) & 18.9 & 6.6 & 5 & Trivial \\
\hline 17 & Mitral valve replacement (St Jude, mechanical valve) & 15.5 & 5.2 & 10 & Mild \\
\hline 18 & Mitral valve replacement (Carbomedics, mechanical valve) & 6.3 & 2.2 & 3 & Mild \\
\hline
\end{tabular}

*Hancock and Mosaic valves: Medtronic, Minneapolis, Minn; Perimount and Starr-Edwards valves: Edwards Lifesciences, Irvine, Calif; Carbomedics valves: LivaNova, London, United Kingdom; St Jude valves: Minneapolis, Minn.

prosthesis interference, however, Testa and colleagues ${ }^{15}$ had to snare the CoreValve and pull it up into the ascending aorta and out of the aortic valve annulus. The patient survived and underwent a successful transcatheter SAPIEN

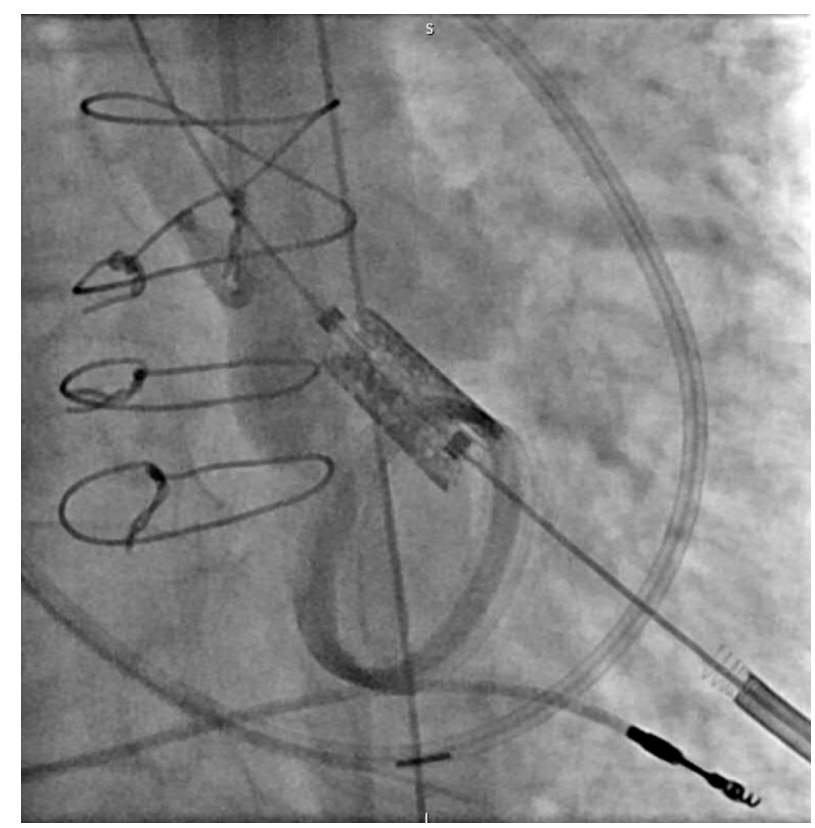

VIDEO 1. Transapical transcatheter balloon expandable aortic valve insertion in a patient with a previous mechanical mitral valve prosthesis. Video available at: http://www.jtcvsonline.org/article/S0022-5223(17) 30637-2/addons. valve insertion 2 months later. These cases substantiate the potential for unsuccessful transcatheter aortic valve insertion in the setting of previous mitral valve replacement.

Other investigators, however, have reported successful valve insertion without interference with the previous mitral valve prosthesis. Asil and colleagues ${ }^{14}$ described successful CoreValve insertion in 6 patients; Soon and colleagues ${ }^{22}$ reported successful SAPIEN valve insertion in 10 patients; and Sari and colleagues ${ }^{10}$ described successful SAPIEN XT valve insertion in 6 patients. Multiple additional case reports and small case series also have been published using both balloon expandable and self-expanding devices. $^{7,9,12,13,16}$ The accumulated preponderance of available literature would support transcatheter aortic valve insertion to be safe and effective after previous mitral valve replacement.

Our analysis adds additional support to the safety and effectiveness of the procedure. It is our sense that there are 2 aspects integral to a successful outcome. The first is an in-depth understanding of the anatomy of the aortic valve and left ventricular outflow tract and the relationship to the mitral valve prosthesis, which we believe is probably best obtained with cardiac gated multidetector computed tomography angiography. The second, and most important, aspect is a thorough comprehension by the multidisciplinary heart team of the anatomy as it relates to the transcatheter valve device and proposed deployment. In Latin, it would be defined as "finis orihine pendet" (ie, "the end depends on the beginning"). 
TABLE 3. Operative data

\begin{tabular}{lllll}
\hline Patient & Transcatheter valve prosthesis* & Arterial access method & Transcatheter valve deployment depth $\dagger$ & Postdilation \\
\hline 1 & SAPIEN & Transapical & $50: 50$ & No \\
2 & SAPIEN & Transapical & $40: 60$ & No \\
3 & SAPIEN XT & Transfemoral & $50: 50$ & No \\
4 & SAPIEN XT & Transfemoral & $70: 30$ & No \\
5 & SAPIEN XT & Transfemoral & $50: 50$ & No \\
6 & CoreValve & Transfemoral & $-2 \mathrm{~mm}$ & No \\
7 & CoreValve & Transfemoral & $50: 50$ & No \\
8 & SAPIEN XT & Transfemoral & $50: 50$ & No \\
9 & CoreValve & Transaortic & $-6 \mathrm{~mm}$ & Yes \\
10 & SAPIEN S3 & Transfemoral & No images available & No \\
11 & Evolut & Transfemoral & $-3 \mathrm{~mm}$ & No \\
12 & SAPIEN S3 & Transfemoral & $50: 50$ & No \\
13 & Evolut & Transfemoral & $-4 \mathrm{~mm}$ & No \\
14 & SAPIEN S3 & Transfemoral & $50: 50$ & No \\
15 & Evolut & Transaortic & $-1 \mathrm{~mm}$ & No \\
16 & CoreValve & Transfemoral & $-5 \mathrm{~mm}$ & No \\
17 & Evolut & Transfemoral & $-1 \mathrm{~mm}$ & No \\
18 & SAPIEN S3 & Transfemoral & $50: 50$ & \\
\hline
\end{tabular}

*SAPIEN, SAPIEN XT, and SAPIEN S3 valves: Edwards Lifesciences, Irvine, Calif; CoreValve and Evolut valves: Medtronic, Minneapolis, Minn. †The position of the deployed transcatheter valve was recorded differently for the 2 types of valves. For balloon expandable valves, the deployment position was recorded as the percent of valve length above and below the nadir of the noncoronary sinus just before balloon inflation (eg, $50 \%$ above and $50 \%$ below the nadir). For the self-expanding valves, the deployment position was recorded as the final depth of the valve below the noncoronary sinus.

We report successful standard transcatheter aortic valve insertion in patients with mitral valve mechanical prostheses. In this series of 10 patients, the median aortic annulus-mitral valve prosthesis distance was $4.1 \mathrm{~mm}$, but it ranged from 0 to $7.5 \mathrm{~mm}$, which was apparently enough in each case to avoid interference with the mitral

TABLE 4. Follow-up echocardiography data

\begin{tabular}{|c|c|c|c|c|}
\hline \multirow[b]{2}{*}{ Patient } & \multirow[b]{2}{*}{$\begin{array}{c}\text { Time from } \\
\text { operation to last } \\
\text { echocardiography } \\
(y)\end{array}$} & \multirow{2}{*}{$\begin{array}{c}\text { Aortic valve } \\
\begin{array}{c}\text { Paravalvular } \\
\text { regurgitation } \\
\text { grade }\end{array} \\
\end{array}$} & \multicolumn{2}{|c|}{ Mitral valve } \\
\hline & & & $\begin{array}{c}\text { Mean } \\
\text { diastolic } \\
\text { gradient } \\
(\mathbf{m m} \mathrm{Hg})\end{array}$ & $\begin{array}{c}\text { Regurgitation } \\
\text { grade }\end{array}$ \\
\hline 1 & 3.4 & Trivial & 4 & Trivial \\
\hline 2 & 0.01 & Trivial & Not recorded & Trivial \\
\hline 3 & 0.5 & Trivial & 5 & Mild \\
\hline 4 & 1.1 & Mild & 3 & Trivial \\
\hline 5 & 1.4 & Trivial & 2 & Trivial \\
\hline 6 & 1.0 & Trivial & 6 & Trivial \\
\hline 7 & 0.8 & Trivial & 4 & Trivial \\
\hline 8 & 0.1 & Mild & 2 & None \\
\hline 9 & 0.01 & Mild & 10 & Trivial \\
\hline 10 & 0.1 & Trivial & 4 & Trivial \\
\hline 11 & 0.6 & Mild & 8 & Trivial \\
\hline 12 & 0.2 & Mild & 5 & Trivial \\
\hline 13 & 0.5 & Mild & 4 & Trivial \\
\hline 14 & 0.01 & None & 3 & Mild \\
\hline 15 & 0.2 & Mild & 7 & Trivial \\
\hline 16 & 0.1 & Trivial & 4 & Trivial \\
\hline 17 & 0.1 & Mild & 5 & Mild \\
\hline 18 & 0.1 & None & 3 & Mild \\
\hline
\end{tabular}

mechanical prosthesis. It seems reasonable to expect that successful transcatheter valve insertion in this setting can be predicted a priori based on a minimum distance; however, valve insertion was successful in 2 patients with balloon expandable valves and in 2 with self-expanding valves even when the distance was $1 \mathrm{~mm}$ or less. Is that just folly that has succeeded? Our experience is limited to these 18 patients, but most published data report success with both transcatheter valve devices. ${ }^{7,9,10,12-14,16,22}$

We also analyzed our transcatheter experience in the setting of a previous mitral valve repair. Our review of PubMed (http://www.ncbi.nlm.nih.gov/pubmed; accessed December 13, 2016; key words transcatheter aortic valve and mitral annuloplasty) identified only 1 related case report by Bruschi and colleagues ${ }^{16}$ from the Milan group. The authors noted a successful outcome with insertion a 29-mm CoreValve. Our case series adds 4 additional patients successfully operated, but with balloon expandable valves. It seems reasonable to expect that transcatheter aortic valve insertion would be relatively safe and effective in this setting given the native aortomitral valve annulus fibrosus and anterior leaflet as compared with the counterparts of the mitral valve prosthesis. This is speculative, however, as the published experience is based on only 5 cases.

This case series is limited by the single-center retrospective review of only 18 patients. We do not know if any patients were denied operation on the grounds of previous mitral valve operation. Given the small number of patients analyzed, the study is at risk of both type I (ie, 
false positive) and II statistical errors (ie, false negative). Particular to the present study, the error is more likely to be in the realm of a type II statistical error by concluding transcatheter valve insertion a safe and effective procedure after previous mitral valve operation. We would have liked to assess for potential differences between the respective transcatheter valve devices, but the limited number of patients prevents stratifying outcomes based on device selection.

Transcatheter aortic valve insertion was safely and effectively performed in this small series of patients after previous mitral valve operation. Procedure success was achieved with both balloon expandable and self-expanding devices and was independent of arterial access method. The aortic annulus-mitral valve prosthesis distance did not appear to influence procedural success in this series of patients. It remains unknown whether the distance should influence choice of transcatheter valve insertion device. Further study is warranted, but transcatheter valve insertion should not be denied strictly on the basis of a previous mitral valve operation.

\section{Conflict of Interest Statement}

Authors have nothing to disclose with regard to commercial support.

\section{References}

1. Leon MB, Smith CR, Mack M, Miller DC, Moses JW, Svensson LG, et al. Transcatheter aortic-valve implantation for aortic stenosis in patients who cannot undergo surgery. N Engl J Med. 2010;363:1597-607.

2. Smith CR, Leon MB, Mack MJ, Miller DC, Moses JW, Svensson LG, et al. Transcatheter versus surgical aortic-valve replacement in high-risk patients. N Engl J Med. 2011;364:2187-98.

3. Adams DH, Popma JJ, Reardon MJ, Yakubov SJ, Coselli JS, Deeb GM, et al. Transcatheter aortic-valve replacement with a self-expanding prosthesis. N Engl J Med. 2014;370:1790-8.

4. Popma JJ, Adams DH, Reardon MJ, Yakubov SJ, Kleiman NS, Heimansohn D, et al. Transcatheter aortic valve replacement using a self-expanding bioprosthesis in patients with severe aortic stenosis at extreme risk for surgery. $J$ Am Coll Cardiol. 2014;63:1972-81

5. Leon MB, Smith CR, Mack MJ, Makkar RR, Svensson LG, Kodali SK, et al. Transcatheter or surgical aortic-valve replacement in intermediate-risk patients. N Engl J Med. 2016;374:1609-20.

6. Sarkar K, Speciale G, Ussia GP. CoreValve implant failure in the presence of mechanical mitral prosthesis: importance of assessing left ventricular outflow tract. Catheter Cardiovasc Interv. 2015;85:920-4.
7. Bajur R, Kiaii B, Teefy PJ, Diamantouros P, Harle C, Goela A, et al. Transcatheter ACURATE-TA aortic valve implantation in a patient with a previous mechanical mitral valve. Ann Thorac Surg. 2015;100:e115-7.

8. Poulin F, Lamarche Y, Le VHV, Doucer M, Romero P, Genereux P. Transcatheter aortic valve replacement in a patient with a previous bioprosthetic mitral valve replacement: report of a delayed fatal interaction. Can J Cardiol. 2016;32: 270. e1-2.

9. Maluenda G, Caorsi C, Baeza C. Transfemoral implantation of CoreValve Evolut-R aortic prosthesis in patient with prior ball-cage mechanical mitral prosthesis. Cardiovasc Revasc Med. 2016;17:287-9.

10. Sari C, Baştuğ S, Ayhan H, Kasapkara HA, Durmaz T, Keles T, et al Transfemoral aortic valve implantation in severe aortic stenosis patients with prior mitral valve prosthesis. Postepy Kardiol Interwencyjnej. 2015;11:304-11.

11. Rodes-Cabau J, Dumont E, Miro S, Doyle D, Larouchelliere RD, Clavel MA, et al. Apical aortic valve implantation in a patient with a mechanical valve prosthesis in mitral position. Circ Cardiovasc Interv. 2008;1:233.

12. Dumonteil N, Marcheix B, Berthoumieu P, Massabuau P, Decramer I, Fournial G, et al. Transfemoral aortic valve implantation with pre-existent mechanical mitral prosthesis. JACC Cardiovasc Interv. 2009;9:897-8.

13. Bruschi G, De Marco F, Oreglia J, Colombo P, Fratto P, Lullo F, et al Percutaneous implantation of CoreValve aortic prostheses in patients with a mechanical mitral valve. Ann Thorac Surg. 2009;88:e50-2.

14. Asil S, Sahiner L, Ozer N, Kaya EB, Evranos B, Canpolat U, et al. Transcatheter aortic valve implantation in patients with a mitral prosthesis: single center experience and review of literature. Int J Cardiol. 2016;221:390-5.

15. Testa L, Gelpi G, Bedogni F. Transcatheter aortic valve implantation in a patien with mechanical mitral prosthesis: a lesson learned from an intraventricular clash. Catheter Cardiovasc Interv. 2013;82:E621-5.

16. Bruschi G, De Marco F, Oreglia J, Colombo P, Barosi A, Einaudi A, et al Transcatheter self-expandable aortic valve implantation after undersized mitral annuloplasty. Ann Thorac Surg. 2011;92:1881-3.

17. Kappetein AP, Head SJ, Genereux P, Piazza N, van Mieghem NM Blackstone EH, et al. Updated standardized endpoint definitions for transcatheter aortic valve implantation: The Valve Academic Research Consortium-2 consensus document. J Thorac Cardiovasc Surg. 2013;145:6-23.

18. SAPIEN. Instructions for use: Edwards SAPIEN Transcatheter heart valve with RetroFlex 3 delivery system. Available at: http://www.fda.gov/downloads/ Adviso...orySystemDevicesPanel/UCM262938.pdf. Accessed August 19, 2015.

19. SAPIEN XT. Instructions for use. Edwards SAPIEN XT: Transcatheter heart valve with NovaFlex transfemoral kit. Available at: https://www.accessdata.fda.gov/ cdrh_docs/pdf13/P130009d.pdf. Accessed August 19, 2015.

20. SAPIEN S3. Instructions for use. Edwards SAPIEN 3: Transcatheter heart valve with the Edwards Commander Delivery System. Available at: http://www. accessdata.fda.gov/cdrh_docs/pdf14/P140031c.pdf. Accessed August 19, 2015.

21. CoreValve. Instruction for use. Medtronic: CoreValve system. Available at: http:/ www.accessdata.fda.gov/cdrh_docs/pdf14/P140031c.pdf. Accessed August 19, 2015 .

22. Soon JL, Ye J, Lichtenstein SV, Wood D, Webb JG, Cheung A. Transapical transcatheter aortic valve implantation in the presence of a mitral prosthesis. J Am Coll Cardiol. 2011;58:715-21.

Key Words: transcatheter aortic valve insertion, transcatheter aortic valve replacement, mitral valve replacement, mitral valve repair, complication, aortic stenosis 